\title{
Pavement Deterioration Rate and Maintenance Cost for Low-Volume Roads
}

\author{
Turki I. A I-Suleiman (O baidat) ${ }^{1}$, Subhi M. B azlamit ${ }^{1}$, Mahmoud A zzama ${ }^{1}$, Hesham S. A hmad ${ }^{1 *}$
}

${ }^{1}$ A I-Zaytoonah University of J ordan, Department of Civil and Infrastructure Engineering, P.O. Box: 130, A mman 11733, J ordan

\begin{abstract}
Allocated budgets for maintenance of road networks are normally limited. Therefore, not all roads receive the required attention they deserve in a timely manner. These roads are left to deteriorate until the next maintenance round. The cost associated with delayed maintenance is significantly excessive. A Pavement Maintenance M anagement System (PM M S) can be a useful tool for evaluation, prioritization of M aintenance and Rehabilitation $(M \& R)$ projects, and determination of funding requirements and allocations. The pavement condition is normally indexed using a parameter called Pavement Condition Index $(\mathrm{PCI})$ which represents an overall assessment of surface defects by type, severity and extent. Periodic collections of $\mathrm{PCl}$ over time for different sections within the roadway network provide an approach to monitor changes in pavement serviceability over time and can produce useful data to predict and evaluate required maintenance solutions and their associated cost. The researchers intend to use available data collected over the span of a year and a half on sections within the roadway network at the campus of Al-Zaytoonah University of Jordan (ZUJ) to study the relation between the maintenance cost and the pavement deterioration rate. This study may incorporate variables such as pavement age, traffic volumes, maintenance history and pavement condition assessment results. The available records of $\mathrm{PCl}$ will be analyzed and the findings will be clearly presented. The practical inclusion of the findings within the current PM M S used at the university will also be detailed.
\end{abstract}

Keywords: condition, deterioration, maintenance, pavements, serviceability

\section{Introduction}

The aim of PMMS is the achievement of better and smoother roads at a reasonable cost. According to Shahin and Walther [1] and Shahin [2], the maintenance at early stages of pavement deterioration proved to produce large saving before the start of the costly decline in pavement condition. Therefore, funding is normally allocated in the most efficient and

\footnotetext{
*Corresponding author: $\underline{\text { h.ahmad@ zuj.edu.jo }}$
} 
economic manner to allow engineering pavement managers to employ an efficient decisionmaking process. Good pavement management systems require the collection of substantial amounts of road condition data over time. This can be used in the development of pavement deterioration models. The monitoring of pavement deterioration over time is the backbone of a pavement management system and is used to determine several fundamentals, including the rate of asset degradation at the project and network levels. Furthermore, it aids in the evaluation of remaining life and in the scheduling of future maintenance.

In this particular project, the pavement condition was evaluated using on a number of occasions where each section was evaluated for the surface defects including various types of flexible pavement failures such as cracking and other surface defects [3]. In addition, deterioration can lead to a reduction in ride quality as reported by some researchers [4]. Others have developed composite pavement condition indices based on pavement surface condition and ride quality [5]. In this project, the pavement condition was evaluated using the Pavement Condition Index (PCI) as developed by Shahin and Walther [1] and Shahin [2].

In the paved area of this study, traffic loading is not the leading contributor to pavement failures. Weather-related factors such as climate cycles of temperature and precipitation are the leading causes of distresses such as longitudinal and transverse cracking. Researchers have noted that pavement performance has shown that with the exception of longitudinal and wheel track cracking formation, the roughness of the road increases with additional precipitation [6]. Pavements experience thermal cracking due to compressive and tensile stress when the temperature fluctuates. Smith et al. [7] showed a dependence between temperature and pavement deterioration, where a rise in temperature leads to the development of rutting and propagation of cracking in the pavement. In some areas, thawing during the spring may result in deformation of pavement leading to fatigue and wheel path cracking [8]. In addition, some researchers suggest that snowstorms and floods can worsen road conditions by generating failure and cracking [9].

\section{Literature Review}

Some researchers have studied the relation between maintenance cost and pavement deterioration rate for roads.

George et al. [10] developed equations for predicting pavement deterioration. The authors employed over a 2-years period of historical information that includes structural information, traffic volume and pavement condition data. The studied areas (paved areas with asphalt surfacing) were classified into three groups including flexible pavements with no overlay, flexible pavements with one or more overlay(s), and composite pavements. In all the three equations developed for the three classifications, age of the pavement was found to be the most significant variable to predict road serviceability among other variables of traffic volume and weight, and the structural makeup of the pavement.

Shahin et al. [11] studied the economic effect of different M\&R strategies. The different strategies were applied to pavement sections in a studied paved network. The results showed the economic effectiveness of asphalt overlay compared with other strategies. MicroPAVER pavement management system was used in this study to produce deterioration curves and work planning techniques for the different M\&R strategies.

Tinni [12] has argued that the estimation of pavement maintenance costs for long periods of time mostly comes with inaccurate end results. His paper has demonstrated the inaccuracy of the used methodology in Australia. The research concluded that a way to reach a reasonable accuracy is to carry out a detailed historical long term cost study for different pavements, which is rarely to be applied. The researcher also concluded that with a time period of over 20 years, the total maintenance cost of concrete pavement is at least 19 times less than for flexible pavements with the same traffic volume. 
Babashamsi et al. [13] have analyzed current methods used for Life-Cycle Cost Analysis (LCCA). LCCA is an economic analysis process used to evaluate the cost-efficiency of alternatives in order to obtain optimum pavement life-cycle costs. LCCA takes into consideration the total economic worth by analyzing the initial cost and discounted future cost including maintenance, use, reconstruction, rehabilitation, restoring, and resurfacing costs, over the life of the project segment. Another study on LCCA by Wang Z. and Wang $\mathrm{H}$ [14] aimed at developing LCCA model to evaluate the impact of pavement preservation on agency cost (M\&R work) and Vehicle Operating Cost (VOC), and estimating the optimal time of pavement preservation treatment. The study used long-term data of the International Roughness Index (IRI), a parameter for evaluating the functional condition of the pavement. It was found that the optimal timing to apply preservation treatment depends on the type of treatment, the existing condition before the treatment (or pavement age), and the effect of treatment on pavement performance deterioration. The results also showed that the cost benefits in VOC are greater than the benefit in agency cost, while the optimal timing calculated based on VOC is always earlier than the optimal timing calculated based on agency cost.

Previous studies have investigated the relation between maintenance cost and pavement condition. However, this study concentrates on the relation between maintenance cost and pavement deterioration when the paved road subjected to low-volume vehicles, and the deterioration of pavement is caused mainly by the weather.

\section{Objective and Scope}

The aim of this research is to develop formulas that relate maintenance cost with pavement deterioration rate for low-volume roads. This formula will depend on data collection and analysis from the road network in Al-Zaytoonah University of Jordan (ZUJ). A Pavement Maintenance Management System (PMMS) for the road network in ZUJ was previously developed and presented in research papers [15].

This research incorporated the following stages:

- Developing a database inventory for the road network at ZUJ based on a Geographic Information System (GIS) map. This inventory includes the engineering properties for each section in the road network.

- Conducting the first-round evaluation to the pavement condition following the procedures that depend on calculating PCI for each road section developed by Shahin and Walther (1990), and by using PAVER system software developed by the U.S. Army Corps of Engineering.

- Based on the results of pavement condition evaluation, priorities of the areas that need Maintenance and Rehabilitation $(M \& R)$ were decided. After this, the required work of M\&R was decided and the required quantities and budget were estimated.

- Conducting the second round of evaluation to the pavement condition and using PAVER system to estimate the reduction on PCI for each road section.

- Studying the relation between the maintenance cost and the pavement deterioration rate and developing calculation equations by conducting regression analysis.

\section{Process}

The first step in establishing a PMMS for the paved network in the area of the study was to prepare an inventory that organizes the paved areas for $M \& R$ management using the method presented by Shahin and Walther [1] and Shahin [2]. The paved network in ZUJ was divided into four branches. Only the results for one branch named Ring Road (RINGR) 
consisting of 46 sections will be used for the purpose of this paper. For practical objectives, sections were classified to identify areas with relatively consistent characteristics, such as dimensions, surface condition, traffic type and volume, and construction history. It should be noted that the pavement thickness and composition, the traffic type and volume for the different sections in the studied branch are relatively consistent.

The second step is to conduct a field inspection to evaluate the current condition of the different paved sections using Pavement Condition Index (PCI) method [1, 2].]This method uses a scale of 100 points to rate the condition of each road section that can be presented in seven pavement condition classifications as shown in Figure 1.

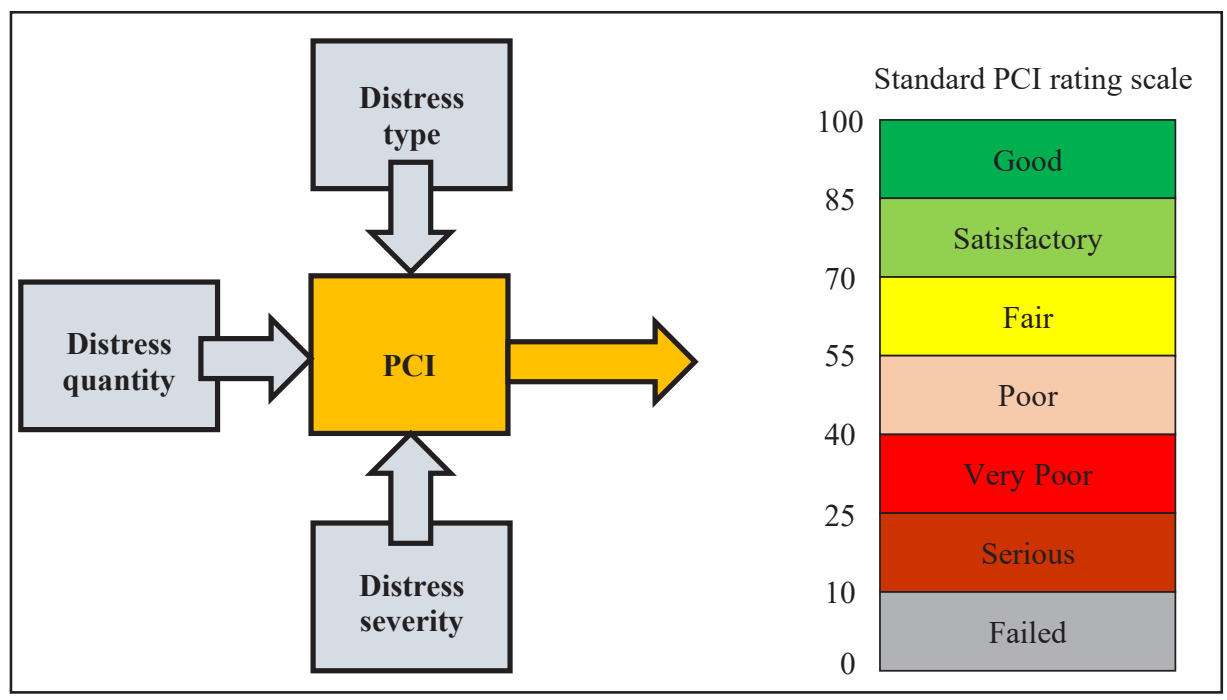

Fig. 1. Rating scale used for Pavement Condition Index (PCI) method (Source: Shahin (2005))

In this study, two cycles of field inspections were conducted with a time period of 1 year. Between the first cycle and the second, M\&R project was implemented on some of the poor, very poor, serious and failed sections in ZUJ road network. The areas that need M\&R were decided regarding the pavement condition evaluation, the location importance and the available budget. Hence, the number of PCI high rated sections has increased in 2018 compared with what was in 2017 , while the number of low rated sections has decreased, as shown in Figure 2. 


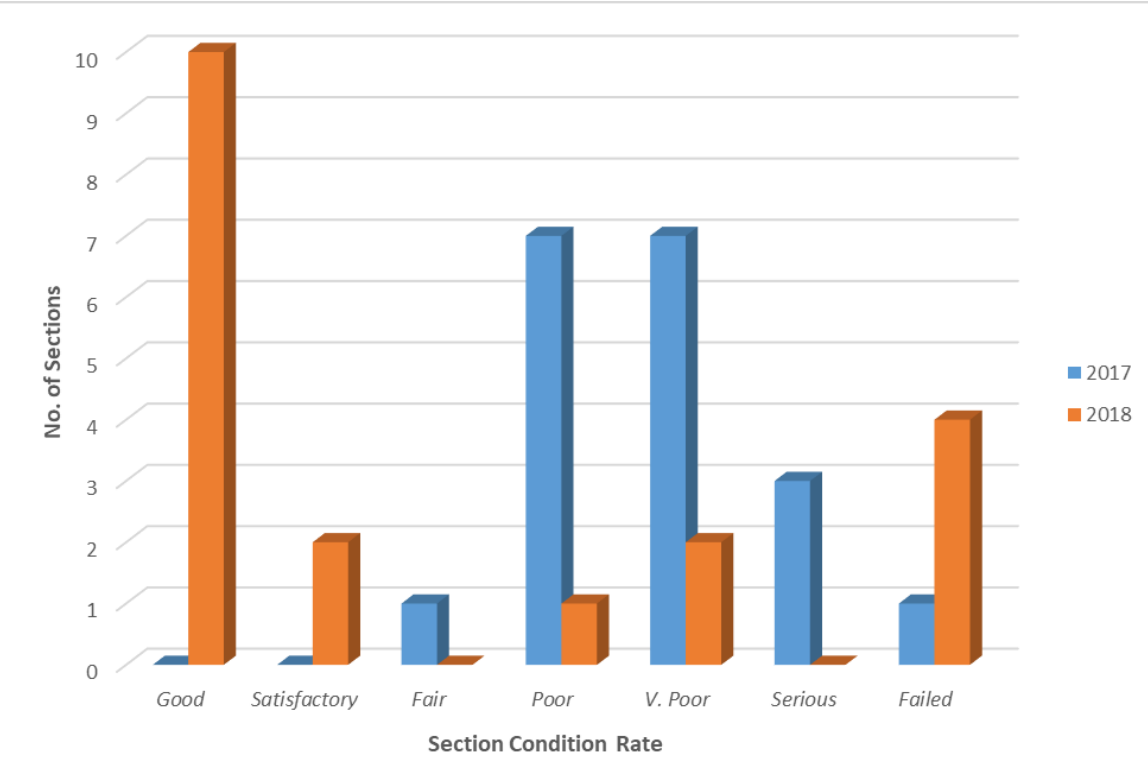

Fig. 2. Comparison of Pavement Condition between 2017 and 2018

The results of the field inspections and the calculations of PCI values for the two cycles of the years 2017 and 2018 were conducted by using Paver 7 software. Figure 3 shows the PCI results for the road section where no M\&R works have executed, while Figure 4 shows the results for the maintained sections. The 100 points scale and the seven colourcoded layers for the pavement conditions were used in the two figures.

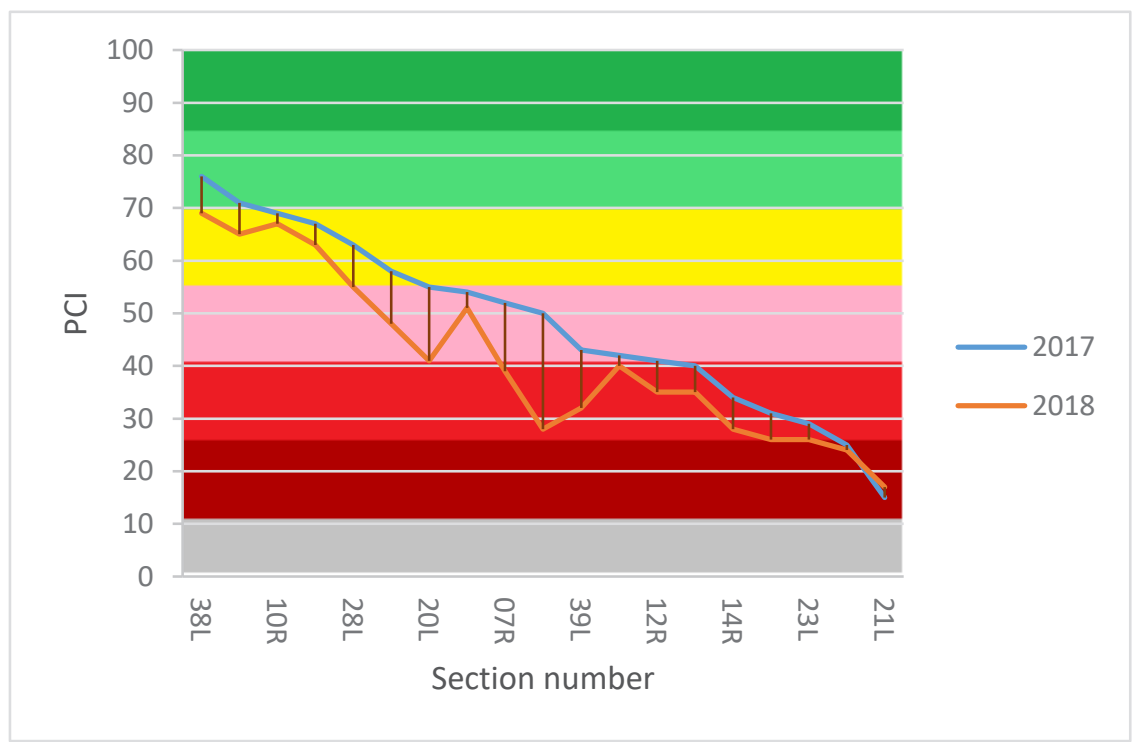

Fig. 3. PCI Results for Road Sections with no M\&R Works 


\section{EPPM2018}

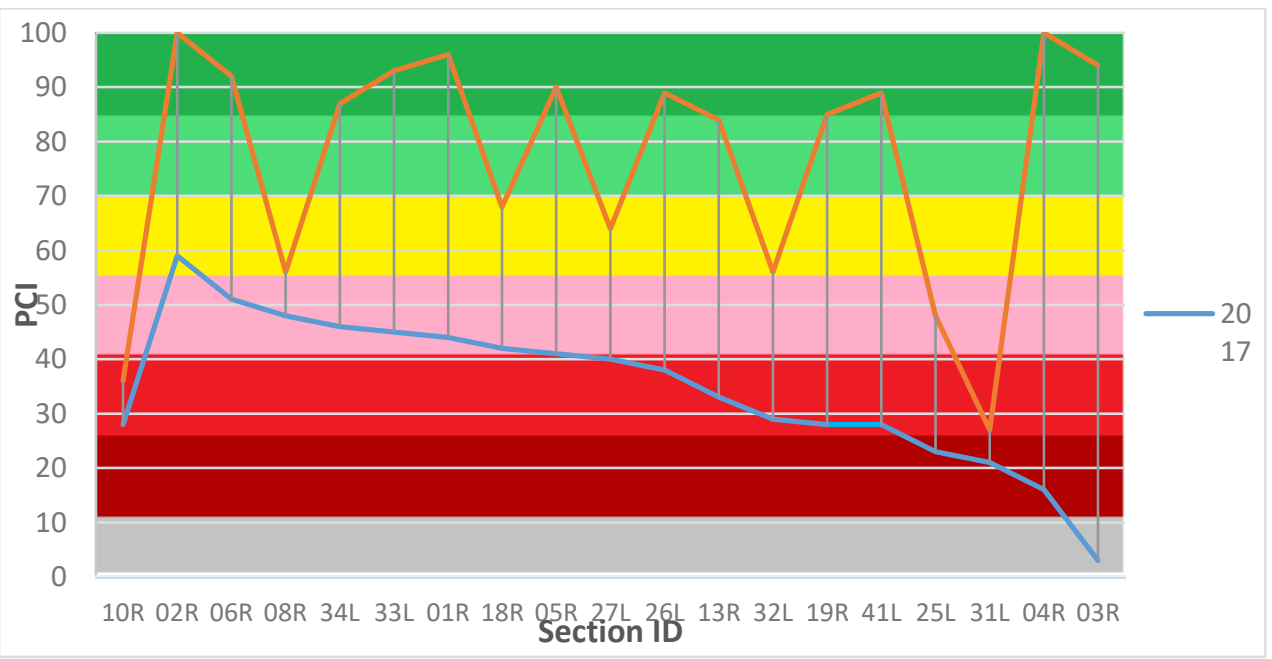

Fig. 4. PCI Results for Road Sections with M\&R Works

\section{Results}

The aim of this study is to develop a relation between the maintenance cost and deterioration rate. To fulfil this aim, the paved areas subjected to maintenance and repair were classified into three groups regarding their condition evaluation prior to the M\&R implementation. The three groups include Poor, very poor, and failed and serious pavement condition ratings to reflect the quantity, severity and type of distresses in the road sections prior to the M\&R project implementation. The type of repairs used for the defected areas depended on the type and severity of each defect. Figure 4 represents examples of repair types may be used for certain conditions of pavement.

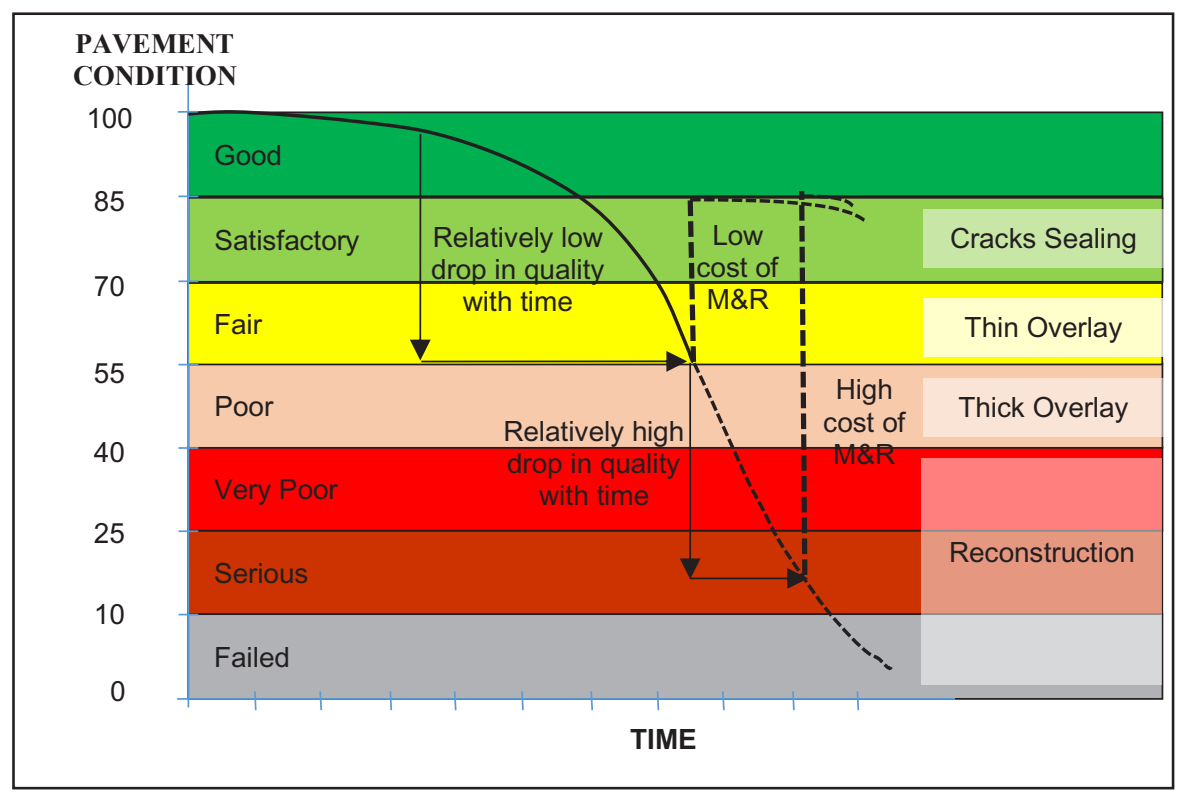

Fig. 5. Examples of repair types may be used with PCI evaluation 
The sections subjected to M\&R applications were used to study the relation between improvement or change in the pavement condition $(\triangle \mathrm{PCI})$ and maintenance cost. The relations were studied for the whole ratings as well as for the classified groups of pavement, as shown in Figure 6.

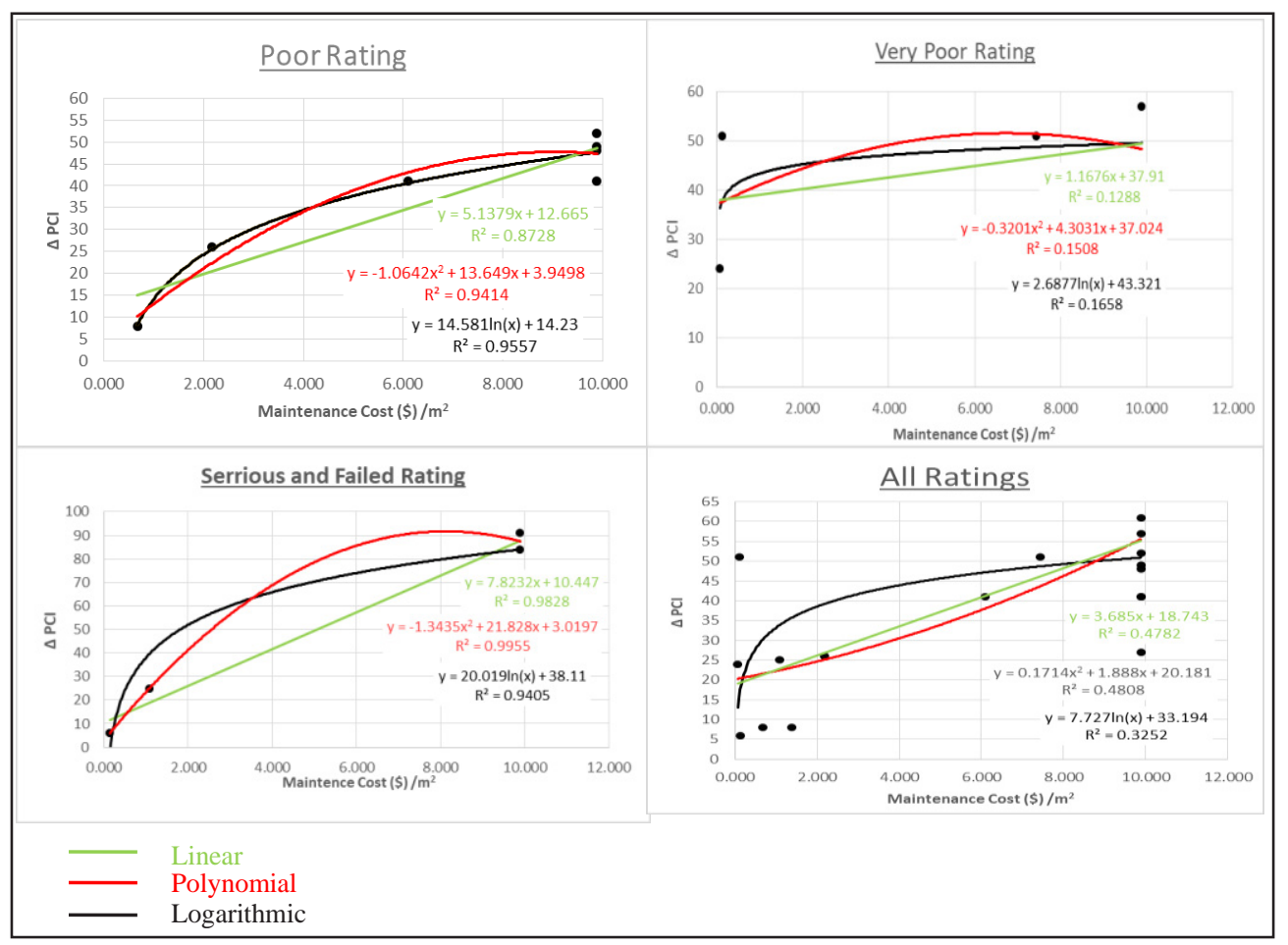

Fig. 6. Relation of $\triangle \mathrm{PCI}$ and maintenance cost

As shown in Figure 6, regression analysis was conducted by using three types of relations including linear, polynomial and logarithmic equations. The analysis was conducted and presented for the results of the whole maintained sections as well as for the separated groups of poorly rated sections, very poor rated sections, and serious and failed sections. The results were summarized in Table 1 . Also, the detailed calculations for $\triangle \mathrm{PCI}$ and maintenance cost per meter square are shown in Tables 2 and 3.

Table 1. Formulas developed to relate maintenance cost and deterioration rate of paved areas

\begin{tabular}{|c|c|c|c|c|c|c|c|}
\hline \multirow{2}{*}{ Rating } & \multirow{2}{*}{$\begin{array}{c}\# \\
\text { of } \\
\text { sec. }\end{array}$} & \multicolumn{2}{|c|}{ Linear } & \multicolumn{2}{|c|}{ Polynomial } & \multicolumn{2}{|c|}{ Logarithmic } \\
\hline & & Equation & $\mathrm{R}^{2}$ & Equation & $\mathrm{R}^{2}$ & Equation & $\mathrm{R}^{2}$ \\
\hline Poor & 7 & $\begin{array}{l}\Delta \mathrm{PCI}= \\
5.1379\end{array}$ & 0.8728 & $\begin{array}{c}\Delta \mathrm{PCI}=- \\
1.0642(\mathrm{Mc})^{2}\end{array}$ & 0.9414 & $\begin{array}{l}\Delta \mathrm{PCI}= \\
14.581\end{array}$ & 0.9557 \\
\hline $\begin{array}{l}\text { Very } \\
\text { Poor }\end{array}$ & 7 & $\begin{array}{l}\Delta \mathrm{PCI}= \\
1.1676\end{array}$ & 0.1288 & $\begin{array}{c}\Delta \mathrm{PCI}=- \\
0.3201(\mathrm{Mc})^{2}\end{array}$ & 0.1508 & $\begin{array}{l}\Delta \mathrm{PCI}= \\
2.6877\end{array}$ & 0.1658 \\
\hline
\end{tabular}




\begin{tabular}{|c|c|c|c|c|c|c|c|}
\hline \multirow{2}{*}{ Rating } & \multirow{2}{*}{$\begin{array}{c}\# \\
\text { of } \\
\text { sec. }\end{array}$} & \multicolumn{2}{|c|}{ Linear } & \multicolumn{2}{|c|}{ Polynomial } & \multicolumn{2}{|c|}{ Logarithmic } \\
\hline & & Equation & $\mathrm{R}^{2}$ & Equation & $\mathrm{R}^{2}$ & Equation & $\mathrm{R}^{2}$ \\
\hline $\begin{array}{l}\text { Failed } \\
\&\end{array}$ & 4 & $\begin{array}{l}\Delta \mathrm{PCI}= \\
7.8232\end{array}$ & 0.9828 & $\begin{array}{c}\Delta \mathrm{PCI}=- \\
1.3435(\mathrm{Mc})^{2}\end{array}$ & 0.9955 & $\begin{array}{l}\Delta \mathrm{PCI}= \\
20.019\end{array}$ & 0.9405 \\
\hline $\begin{array}{c}\text { All } \\
\text { Ratings }\end{array}$ & 18 & $\begin{array}{c}\Delta \mathrm{PCI}= \\
3.685 \mathrm{Mc} \\
+18.743\end{array}$ & 0.4782 & $\begin{array}{c}\Delta \mathrm{PCI}= \\
0.1714(\mathrm{Mc})^{2} \\
+1.888\end{array}$ & 0.4808 & $\begin{array}{c}\Delta \mathrm{PCI}= \\
7.727 \\
\ln (\mathrm{Mc})\end{array}$ & 0.3252 \\
\hline
\end{tabular}

$\mathrm{Mc}=$ Maintenon cost per square meter in U.S Dollar (\$).

Table 2. Detailed Calculations for Sections after Maintenance

\begin{tabular}{|c|c|c|c|c|c|c|}
\hline Section ID & $\begin{array}{l}\text { Area } \\
\left(\mathrm{m}^{2}\right)\end{array}$ & PCI Before & PCI After & $\triangle \mathrm{PCI}$ & $\begin{array}{c}\text { Maintenance } \\
\text { Cost }(\$)\end{array}$ & $\begin{array}{l}\text { Maintenance } \\
\text { Cost }(\$) / \mathrm{m}^{2}\end{array}$ \\
\hline $10 \mathrm{R}$ & 180 & 28 & 36 & 8 & 175 & 1.373 \\
\hline $02 \mathrm{R}$ & 300 & 59 & 100 & 41 & 2100 & 9.887 \\
\hline 06R & 994.2 & 51 & 92 & 41 & 6959 & 9.887 \\
\hline 08R & 370.3 & 48 & 56 & 8 & 175 & 0.667 \\
\hline $34 \mathrm{~L}$ & 570.2 & 46 & 87 & 41 & 2458 & 6.090 \\
\hline $33 \mathrm{~L}$ & 197 & 45 & 93 & 48 & 1379 & 9.887 \\
\hline $01 \mathrm{R}$ & 465.3 & 44 & 96 & 52 & 3257 & 9.887 \\
\hline $18 \mathrm{R}$ & 919.5 & 42 & 68 & 26 & 1414 & 2.172 \\
\hline $05 \mathrm{R}$ & 174.8 & 41 & 90 & 49 & 1224 & 9.887 \\
\hline $27 \mathrm{~L}$ & 2701 & 40 & 64 & 24 & 140 & 0.073 \\
\hline $26 \mathrm{~L}$ & 1183.4 & 38 & 89 & 51 & 98 & 0.117 \\
\hline $13 R$ & 829.6 & 33 & 84 & 51 & 4368 & 7.437 \\
\hline $32 \mathrm{~L}$ & 818 & 29 & 56 & 27 & 5726 & 9.887 \\
\hline $19 \mathrm{R}$ & 301 & 28 & 85 & 57 & 2107 & 9.887 \\
\hline $41 \mathrm{~L}$ & 301 & 28 & 89 & 61 & 2107 & 9.887 \\
\hline $25 \mathrm{~L}$ & 495 & 23 & 48 & 25 & 378 & 1.079 \\
\hline $31 \mathrm{~L}$ & 359 & 21 & 27 & 6 & 35 & 0.138 \\
\hline 04R & 174.8 & 16 & 100 & 84 & 1224 & 9.887 \\
\hline 03R & 95.7 & 3 & 94 & 91 & 670 & 9.887 \\
\hline
\end{tabular}


Table 3. Detailed Calculations for Sections without Maintenance

\begin{tabular}{|c|c|c|c|c|c|c|}
\hline Section ID & $\operatorname{Area}(\mathrm{m} 2)$ & PCI Before & PCI After & $\triangle \mathrm{PCI}$ & $\begin{array}{c}\text { Maintenance } \\
\text { Cost (\$) }\end{array}$ & $\begin{array}{l}\text { Maintenance } \\
\text { Cost }(\$) / \mathrm{m}^{2}\end{array}$ \\
\hline $38 \mathrm{~L}$ & 506 & 76 & 69 & -7 & 0 & 0 \\
\hline 09R & 1411.6 & 71 & 65 & -6 & 0 & 0 \\
\hline $10 \mathrm{R}$ & 711.9 & 69 & 67 & -2 & 0 & 0 \\
\hline $16 \mathrm{R}$ & 1387.3 & 67 & 63 & -4 & 0 & 0 \\
\hline $28 \mathrm{~L}$ & 279 & 63 & 55 & -8 & 0 & 0 \\
\hline $17 \mathrm{R}$ & 191.8 & 58 & 48 & -10 & 0 & 0 \\
\hline $20 \mathrm{~L}$ & 583.4 & 55 & 41 & -14 & 0 & 0 \\
\hline $35 \mathrm{~L}$ & 292.5 & 54 & 51 & -3 & 0 & 0 \\
\hline $07 \mathrm{R}$ & 1750 & 52 & 39 & -13 & 0 & 0 \\
\hline $15 \mathrm{R}$ & 184.6 & 50 & 28 & -22 & 0 & 0 \\
\hline $39 \mathrm{~L}$ & 286.3 & 43 & 32 & -11 & 0 & 0 \\
\hline $40 \mathrm{~L}$ & 588.5 & 42 & 40 & -2 & 0 & 0 \\
\hline $12 \mathrm{R}$ & 234 & 41 & 35 & -6 & 0 & 0 \\
\hline $11 \mathrm{R}$ & 174.2 & 40 & 35 & -5 & 0 & 0 \\
\hline $14 \mathrm{R}$ & 184.6 & 34 & 28 & -6 & 0 & 0 \\
\hline $24 \mathrm{~L}$ & 162 & 31 & 26 & -5 & 0 & 0 \\
\hline $23 \mathrm{~L}$ & 304.25 & 29 & 26 & -3 & 0 & 0 \\
\hline $29 \mathrm{~L}$ & 300 & 25 & 24 & -1 & 0 & 0 \\
\hline $21 \mathrm{~L}$ & 147.2 & 15 & 17 & 2 & 0 & 0 \\
\hline
\end{tabular}

The results indicated the reliance of maintenance cost on the condition evaluation of pavement prior to the M\&R projects execution. Linear regression proved to appropriately represent the relation between the cost of maintenance and the rate of deterioration. The results of $\mathrm{R}^{2}$ calculations indicated a high level of reliability and validity of the equations. The equations can be used as a prediction model for estimating the cost of required maintenance for paved areas with low traffic volume. In future studies, it is recommended to conduct comparative studies to study the effect of the traffic volume and the structure of pavement for broader areas of pavement. This requires conducting more tests and collecting more data during a longer period of the road network life-cycle.

\section{Conclusion}

The developed equations can be used as a prediction model to estimate the required cost for maintaining paved areas depending on information about pavement condition, rate of deterioration and the area for each evaluated section. Values of $\mathrm{R}^{2}$ refers that the equations are representing the results in a good manner, and so the equations can be used for cost prediction. 
Conduction more iterations of PCI evaluation during the coming years and after M\&R projects will help to improve the prediction equations. In the future development of this study, it is recommended to use modern tools and methods for more effective evaluation of the conditions of paved areas, such as using image processing, remote sensing and groundpenetrating radar techniques. Improvement of pavement condition valuation and setting for M\&R work will aim at making the required procedures become more robust.

\section{References}

1. M.Y. Shahin, J.A. Walther, Pavement Maintenance Management for Roads and Streets Using the PAVER System. 1st ed., US A rmy Corps of Engineering (1990)

2. M.Y. Shahin, Pavement Management for Airports, Roads, and Parking Lots. 2nd ed. Springer Science and Business M edia, L LC (2005)

3. K. Patel, B. Prajapati, N. Kanojia, S.J. Chauhan,. Literature R eview on Types of Flexible Pavement Failures, International Journal for Scientific Research \& Development|, 5(2):145-147 (2017)

4. V.L. Ng, A study of deterioration in ride quality on Ohio's highways, Thesis (M .S.), University of Toledo, Ohio, United States (2015), http://utdr.utoledo.edu/thesesdissertations/1861

5. F. Reza, K. Boriboonsomsin, S.M . B azlamit, Development of a Composite Pavement Performance Index ST/SS/05-001, Ohio D epartment of Transportation, Columbus, Ohio, U nited States (2005)

6. W. Li, L. Mills, S., M cNeil, The Implications of Climate Change on Pavement Performance and Design, University Transportation Center, University of Delaware, Newark, DE (2011)

7. J.T. Smith, S.L. Tighe, J.C. A ndrey, B. M ills, Temperature and Precipitation Sensitivity A nalysis on Pavement Performance, Transportation Research Circular, Surface Transportation Weather and Snow Removal and Ice Control Technology, 558571 (2008)

8. N. Jackson, J. Puccinelli, L ong-Term Pavement Performance (LTPP) Data A nalysis Support: National Pooled Fund Study TPF-5(013): Effects of M ultiple Freeze Cycles and Deep Frost Penetration on Pavement Performance and Cost, Nichols Consulting Engineers, Reno, N evada, U nited States (2006)

9. S.S. Shamsabadi, Y.S.H. Tari, R. Birken, M. Wang, Deterioration Forecasting in Flexible Pavements due to Floods and Snow Storms, 7th European W orkshop on Structural Health M onitoring, July 8-11, 2014 La Cité, Nantes, France (2014)

10. K.P. George, A.S. Rajagopal, L.K. Lim, M odels for Predicting Pavement Deterioration, Transportation Research Record: Journal of the Transportation Research Board, 1215, 1-7 (1989)

11. M.Y. Shahin, C. Stock, L. B eckberger, Comparing Pavement Performance and Its Effect on $M$ aintenance and Rehabilitation Cost, 3rd International Conference on M anaging Pavements, 237-245 (1994)

12. A. Tinni, Comparison of M aintenance Costs of Heavy Duty Pavements, Tinni Management Consulting, Eesti Betooniühing, March (2013)

13. P. Babashamsi, N. Y usoff, H. Ceylan, N. N or, H. J enatabadi, Evaluation of pavement life cycle cost analysis: Review and analysis, International Journal of Pavement Research and Technology, $9:$ 241-254 (2016) 
14. Z. Wang, H. Wang, Life-cycle cost analysis of optimal timing of pavement preservation, Frontiers of Structural and Civil Engineering, 11(1) : 17-26 (2017)

15. T.I.A. Obaidat, Z.M . Hamici, S.M . Bazlamit, H.S. A hmad, A ssessment of the Effect of A lligator Cracking on Pavement Condition U sing W SN -I mage Processing, L ecture $N$ otes in $M$ echanical Engineering/ 8th International Conference on Engineering, Project, and Product M anagement (EPPM 2017) : 265-274(2018) 